\title{
REVIEW
}

\section{The management of minor traumatic brain injury}

\author{
P J A Hutchinson, P J Kirkpatrick, J Addison, S Jackson, J D Pickard
}

The past two decades have seen increased interest in the management of major head injury. The introduction of advanced trauma life support ${ }^{1}$ courses within the United Kingdom has made a significant contribution to the initial treatment of patients with severe brain trauma, and addresses the major concerns of early correction of hypoxia and hypotension. However, a working party organised by the Traumatic Brain Foundation acknowledges the difficulties in providing evidence based guidelines for these patients. ${ }^{2}$

In contrast, minor injury attracts much less publicity, despite affecting many more patients and demanding important management decisions. In this review we aim to discuss the management of minor traumatic brain injury, particularly the exclusion of major injury. ${ }^{3}$

The significance of the problem relates to the one million patients who annually attend accident and emergency (A\&E) departments with a head injury in the United Kingdom. ${ }^{5}$ Of these, 800000 have a minor or mild injury, and 80000 are admitted to hospital. The inpatient hospital cost incurred is therefore considerable. Prolonged time off work as a result of persistent postconcussion symptoms adds to the national burden resulting from minor traumatic brain injury.

The definition of minor traumatic brain injury is unsatisfactory for two reasons. Firstly, traditionally the term "head injury" has been applied, but the term "traumatic brain injury" is now often used. Secondly, there is confusion regarding the term "minor." In the past head injuries have been divided according to the Glasgow coma scale (GCS) ${ }^{6}$ as minor (GCS 13-15), moderate (GCS 9-12), and severe (GCS $3-8) .7$ However, there is a difference in the rate of complications between those patients with GCS 15 (the overwhelming majority $^{8}$ ) versus those with GCS $13 / 14 .^{9-11}$ Some investigators therefore subdivide this group of brain injured patients into minor (GCS 15) and mild (GCS $13-14) .^{12}$

In this review, we shall use the term "minor traumatic brain injury" to define patients with GCS 13-15. This term simplifies the classification of severity and indicates the aetiology of the injury and that the brain is the affected organ.

\section{Management in the accident and emergency department}

The initial management decisions about patients with minor traumatic brain injury are made by junior doctors within the $A \& E$ department. The aim is to detect those patients at risk of deterioration of consciousness, mainly as a result of the development of an intracranial haematoma. ${ }^{13}{ }^{14}$. The major risk factors for this complication are decreased level of consciousness and the presence of a skull fracture. ${ }^{9}$ The risk of an intracranial haematoma is one in 120 in patients who are confused but have no fracture, one in 30 in those who are fully conscious with a skull fracture, and one in four if both decreased level of consciousness and a fracture are present. A study of 183 patients who presented to hospital with GCS 15 but subsequently underwent surgery for acute intracranial haematoma highlights these factors. ${ }^{14} \mathrm{~A}$ history of altered consciousness, or symptoms of headache and vomiting, was present in $61 \%$ of the patients. A skull fracture was shown radiographically in $60 \%$ of patients. However, in addition to intracranial haematoma, other causes of deterioration can occur $^{15}$ including seizures. ${ }^{16}$

As a result of these studies, guidelines in the form of criteria have been drawn up to aid the management of patients with traumatic brain injury. ${ }^{10}{ }^{17}$ Recently, there has been considerable interest in the production of guidelines in all branches of medicine, particularly in relation to evidence based medicine. Head injury guidelines were the subject of the Bayer Satellite Symposium to the J Douglas Miller memorial meeting held in October 1996 in Edinburgh. Guidelines have been proposed covering all aspects of brain injury management, but those most applicable to minor traumatic brain injury are criteria for skull films, criteria for admission to hospital, and criteria for computed tomography. Problems have arisen in relation to the basis of guidelines, to what extent clinical practice should be governed by guidelines, and whether they can be effectively implemented. We have shown that improvements in documentation and the provision of proformas have not improved the implementation of head injury guidelines in East Anglia. ${ }^{18}$ Most guidelines are based on a consensus of opinion of experts, but with the increased interest in evidence based medicine it is clear that additions and modifications should be based on a combination of expert 


\section{Table 1 Criteria for skull $x$ ray after recent head injury}

Loss of consciousness or amnesia suspected at any time

Neurological symptoms or signs (including headache and/or vomiting more than twice) Return visits

Cerebrospinal fluid or blood from the nose or ear

Suspected penetrating injury

Scalp bruising, swelling, or laceration down to the bone

Children ( $<5$ years): falls from $>60 \mathrm{~cm}$ or onto a hard surface; tense fontanelle;

suspected non-accidental injury (refer to paediatrician)

Difficulty in assessing the patient (eg, alcohol intoxication, epilepsy, children); inadequate or suspicious history

Note: Skull $x$ ray not necessary if computed tomography to be performed immediately or if an abusive patient is to be admitted immediately.

opinion and high quality evidence. Ideally, guidelines should be governed by standards which in turn should be based on hard evidence. As in other branches of medicine, this would require randomised control trials. It will also be necessary to provide mechanisms for evaluating the distribution, implementation, and effectiveness of guidelines.

There are aspects of brain injury suitable for guidelines and the symposium addressed the agenda for future work. The guidelines quoted in this review are those currently in use in the East Anglian Region, and were derived from the national neurosurgical guidelines, ${ }^{10}{ }^{17}$ with input from a number of specialties including neurosurgery, accident and emergency medicine, and general surgery. These are largely based on expert opinion and current practice, not on randomised controlled trials.

\section{Criteria for skull $x$ ray after recent head injury}

This has been a source of great controversy in Britain, with some radiologists criticising liberal policies on skull radiography which result in large numbers of negative skull films. ${ }^{19} 20$ However, if a skull fracture is detected, the risk of an intracranial haematoma is increased, particularly if the patient is disorientated. ${ }^{92}$ Thus skull films may be considered to direct the decision as to whether to perform computed tomography.

In order to establish guidelines for skull radiography following brain injury, a group of neurosurgeons and radiologists met in Harrogate in 1983 and drew up the Harrogate criteria for skull films after brain trauma. ${ }^{22}$ In East Anglia criteria for skull films after recent brain injury have been formulated as part of regional head injury guidelines (table 1). In addition, clinical judgement is necessary for assessing the force of injury, which requires an accurate history.

Table 2 Criteria for admission to hospital

\footnotetext{
1 Confusion or any other depression of the level of consciousness at the time of examination. If $<5$ years, at any time following the injury

Neurological symptoms or signs even if minor, particularly in children (eg, headache or vomiting more than twice)

Skull fracture on skull $x$ ray or clinical signs of basal skull fracture including

cerebrospinal fluid rhinorrhoea / otorrhoea

Difficulty in assessing the patient (eg, suspected drugs, alcohol, non-accidental injury,

epilepsy, attempted suicide)

Other medical conditions (eg, coagulation disorders)

6 Patient's social conditions or lack of a responsible adult / relative
}

Note: (a) Post-traumatic amnesia $(<2 \mathrm{~min}$ ) or transient unconsciousness with full recovery are not necessarily indications for admission, but if in doubt the patient should be admitted; (b) patients who are sent home should be accompanied by a responsible adult who should receive written advice to return immediately if there is any deterioration.
In contrast to our policy, certain investigators have advocated that skull films only need to be performed if the decision has been made to discharge the patient. ${ }^{23}$ If the patient fulfils the criteria for admission, an immediate skull film is not necessary as the patient will undergo admission for clinical observation. If the patient does not fulfil the clinical criteria for admission and discharge is planned, an immediate skull film is performed. If this reveals a fracture, the patient is deemed at increased risk of developing a haematoma and is then admitted. The exception is where a depressed fracture is suspected and then early skull film should be performed. ${ }^{24}{ }^{25}$ We do not advocate this approach, as skull radiography may detect an unsuspected depressed fracture, and if a fracture is diagnosed there is a strong argument for proceeding to computed tomography. The discovery of a fracture will also heighten the awareness of the inpatient team regarding frequency of neurological observations and length of admission.

The East Anglian criteria attempt to balance fracture detection (and therefore risk of haematoma formation) versus economy in the use of, and risk from, radiographs. We do not advocate skull films in all head injury attendances, but tailor their use to well defined clinical criteria based on expert opinion.

There has also been concern regarding the ability of casualty officers to detect fractures on skull films. A study from Glasgow has shown this to be largely unfounded. ${ }^{26}$ Of 2730 radiographs of the skull, radiologists reported 45 fractures, with casualty officers failing to detect only six.

Of additional concern is the number of other injuries that are missed in a patient with a minor head injury. Gautam and Leonard presented a series of 100 patients with minor traumatic brain injury. ${ }^{27}$ Of these, 30 had fractures in addition to a minor traumatic brain injury. These predominantly affected the facial skeleton $(43 \%)$, skull $(20 \%)$, forearm $(10 \%)$, and spine $(10 \%)$, and $27 \%$ of these fractures were not diagnosed in the A\&E department. A very high index of suspicion is required for extracranial injuries.

\section{Criteria for admission to hospital}

The East Anglian regional guidelines criteria for admission to hospital are listed in table 2 . It is again important to stress that the criteria are an adjunct to clinical judgement. In addition, the mechanism of injury is an important factor. There should be a low threshold for admission for patients who have sustained high velocity injuries. A paper from Denmark has stressed the importance of agitation (defined as unusually troubled behaviour) as a predictor of intracranial pathology. ${ }^{28}$

\section{Criteria for computed tomography scanning in general hospitals}

The controversy regarding skull films and minor traumatic brain injury in Britain has been matched by that over computed tomography and minor traumatic brain injury in the USA. Stein and Ross express concern that 
Table 3 Criteria for computed tomography (CT) in general hospitals

Confusion (GCS <13-14) or worse, persisting after initial assessment and resuscitation Unstable systemic state precluding transfer to neurosurgery

Diagnosis uncertain

Fully conscious but with a skull fracture or following a first fit : admit and consider CT

GCS, Glasgow coma score.

clinical assessment alone is not adequate ${ }^{29}$ and recommend that any patient who has suffered loss of consciousness or amnesia following traumatic brain injury should have urgent cranial computed tomography. ${ }^{30}$ Of 1538 patients with minor traumatic brain injury who were scanned, $265(17.2 \%)$ had an abnormal scan, with 131 fractures and 209 intracranial abnormalities; 58 patients underwent surgery; $40 \%$ of patients with a GCS 13 had abnormalities on tomography. ${ }^{31}$ Mohanty et al, however, argue that routine computed tomography for minor traumatic brain injury is unnecessary and an inefficient use of personnel and equipment. ${ }^{32}$ Of 348 patients scanned, only 12 had abnormal scans with no neurological deficit, and all of these had an uneventful hospital discharge. The reason for the difference in results of these retrospective studies is not clear but may be explained by Stein and Ross using GCS 13-15 for inclusion in their study, and Mohanty et al, GCS 14-15. Different ages, injury aetiology, and timing of scans may also account for the discrepancy. Mohanty et al recognise the need for better prospective studies. There is also debate regarding hospital admission of patients with normal tomographic findings. ${ }^{33}$ Shackford et al advocate computed tomography in all patients with minor traumatic brain injury, and discharge those in whom the scan is negative. ${ }^{34}$ It is well recognised, however, that intracranial lesions may take several hours to develop and can be missed on an early scan. ${ }^{35}$

In the United Kingdom the criteria for computed tomography have changed over the past few years with the increasing availability of scanners in district general hospitals. Teasdale et $a l^{10}$ now advocate scanning patients who are fully conscious but have a skull fracture, and this recommendation has been incorporated into the criteria for computed tomography in general hospitals (table 3 ).

\section{Criteria for consultation with the neurosurgical unit}

The indications for neurosurgical consultation are given in table 4 . Following consultation, approximately $5 \%$ of admitted patients with head injury are transferred to neurosurgical

Table 4 Criteria for consultation with neurosurgical unit

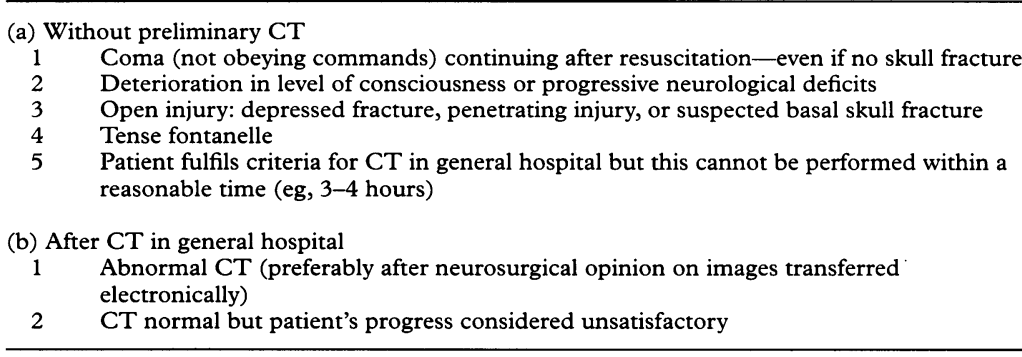

CT, computed tomography. units. ${ }^{5}$ In the United Kingdom, the absolute risk of traumatic intracranial haematoma requiring neurosurgery in adult patients attending $A \& E$ departments with no altered consciousness and no skull fracture is 1:31 370, and for those with no altered consciousness but with a skull fracture it is $1: 81 .^{10}$ The proportion of patients transferred following neurosurgical consultation requires further study.

\section{Inpatient management of minor traumatic brain injury}

If a patient satisfies the criteria for admission their destination depends on the hospital involved. In the United Kingdom, patients with minor traumatic brain injury are admitted to A\&E observation wards, surgical wards, orthopaedic wards, and, rarely, neurosurgical units.

In observation wards the patient usually remains under the care of the A\&E staff. ${ }^{36}$ This has the advantage of ease of admission without involving other teams, and is particularly suitable if the patient's social circumstances are the only indication for admission. In some hospitals, these wards are only open at certain times (for example, weekdays). A study from Guy's Hospital has shown that this influences the decision as to whether the patient is admitted. ${ }^{37}$ When the observation ward was open 51 of 76 patients (67\%) with admission criteria were admitted, but when it was closed and the patient required an inpatient surgical bed only $15 / 51$ patients (29\%) were admitted. Another problem with observation wards is that in the event of deterioration, the general surgical or orthopaedic team is unlikely to have seen the patient before, impairing their assessment of the change of level of consciousness.

In the United Kingdom in the past, patients with minor traumatic brain injury were admitted under the care of general or orthopaedic surgeons. However, as the specialty of $A \& E$ expands it is likely that more patients will be admitted under the care of $\mathrm{A} \& \mathrm{E}$ consultants in observation wards. This approach has the advantage that the initial consultation and subsequent review is made by the same medical team. The neurosurgical unit in Cambridge is unusual in that we admit all patients with minor traumatic brain injury under our care. This has the advantage that computed tomography is readily available and the delay to surgery is minimised.

Following admission, there are several factors to be considered. Neurological observations are performed in order to detect deterioration. There is no consistent pattern to their frequency and duration. Because of the rigid nature of the skull, intracranial bleeding can lead to rapid deterioration in level of consciousness, ending in coning. There are no guidelines for the frequency of observations, but we would recommend half hourly monitoring of the variables listed in table 5. The GCS is the most important observation, as a decline in level of consciousness is the first sign of deterioration, with changes in the other variables occurring late. During this time the patient should not receive anything by mouth and may therefore require an intravenous infu- 
Table 5 Neurological observations

Glasgow coma score

Pupil responses

Pulse

Blood pressure

Limb movement sion. The majority of intracranial haematomas that require urgent evacuation develop within the first 12 hours. Patients should therefore be admitted for at least this time.

Drugs given to patients with minor traumatic brain injury include analgesics, antiemetics, and antibiotics. Codeine phosphate is the most appropriate analgesic. It avoids the neurological and respiratory depression associated with the strong opiates and the depression of platelet function induced by the nonsteroidal anti-inflammatory drugs. Prochlorperazine is a suitable anti-emetic. The routine use of antibiotics is no longer advised for patients with a base of skull fracture. ${ }^{38}$ Those with cerebrospinal fluid leaks should always be admitted and referred to neurosurgeons.

\section{Discharge and follow up}

Following discharge from the A\&E department or the ward, patients are routinely given head injury instruction cards. Ward et al have assessed the benefits of these cards. ${ }^{39}$ They contacted patients who had been discharged from hospital following a minor traumatic brain injury. More than one third had no recollection of receiving a head injury instruction card. Possible explanations for this are that cards are not issued, that relatives receiving cards did not inform the patient, or that the patient had memory loss for this aspect of their management. The authors postulated the latter as the main explanation. However, only seven of 1546 patients stated that the verbal and injury card advice was reassuring or that the symptoms were not bad enough to warrant further reassurance.

Although there is no proven benefit for the use of head injury cards, they are still standard practice. Medicolegal implications may contribute to their continued use. Clear verbal instructions to the carer of the individual should be given irrespective of the use of head injury cards.

\section{The postconcussion syndrome}

The follow up of patients with minor traumatic brain injury is not consistent. Most patients are advised to return to the hospital or visit their general practitioner if they require further treatment. Routine follow up is rarely offered. However, within three months of minor traumatic brain injury over $50 \%$ of patients have post-traumatic symptoms. These together comprise the postconcussion syndrome, a neglected area in the management of minor traumatic brain injury.

Although the aim of this review is to focus on the acute management of apparently minor traumatic brain injury and the exclusion of major injury, we will give a brief outline of the postconcussion syndrome, along with advice on treatment aimed at doctors who treat these patients acutely. There are several detailed reviews on the postconcussion syndrome. ${ }^{40-43}$

The postconcussion syndrome comprises a large number of symptoms that may occur alone or in combination following minor traumatic brain injury. They include headache, dizziness, fatigue, irritability, anxiety, insom- nia, noise sensitivity, and loss of memory. There are two theories of aetiology: (1) the organic theory, which proposes that the syndrome is due to neuronal damage; and (2) the neurosis theory, which suggests that the symptoms are not due to any organic condition but result from an underlying personality disorder. These are addressed in the reviews cited above.

Resolution occurs in most patients within three to six months, but some are affected for many years. There is no specific treatment for the postconcussion syndrome. Education, neuropsychological treatment, and drug treatment have all been used. Education in the form of support, reassurance, and encouraging the patient to return to a normal lifestyle is the most useful form of treatment. Neuropsychological assessment may be useful in determining cognitive impairment. There is no good evidence for the use of drugs, but simple analgesics such as paracetamol may help some patients.

From the perspective of $A \& E$ staff and other doctors who treat patients acutely with minor traumatic brain injury, it is essential to exclude underlying pathology, for example frontal contusions, and to convey information to the general practitioner regarding the nature of the injury and the condition of the patient on discharge. Patients whose symptoms persist after one week should not return to work, and those still symptomatic at one month require further attention. ${ }^{12}$ Advice on management may be obtained from head injury rehabilitation units and a neuropsychology opinion may be appropriate. $A \& E$ medicine may have a role by establishing minor traumatic brain injury follow up clinics. "Headway" is a charitable organisation which supports patients with head injury and produces an information pack for relatives. ${ }^{44}$ The aims of Headway are to give support, encourage research, provide information, and increase awareness.

\section{The future}

The future for the management of minor traumatic brain injury lies with training of medical and nursing staff in the form of formal seminars, the introduction of computerised teaching aids, and implementing and auditing guidelines. More emphasis needs to be placed on the prevention of traumatic brain injury, for example promoting the use of cycle helmets. A greater understanding of the pathophysiology of, and improved treatment of, the postconcussion syndrome represents a further challenge to reducing the morbidity that results from minor traumatic brain injury.

\section{Summary}

Minor traumatic brain injury accounts for the majority of the one million head trauma attendances at $A \& E$ departments in the United Kingdom. Guidelines have been established listing criteria for skull films, admission to hospital, computed tomography, and neurosurgical consultation. These are currently undergoing revision and were the subject of a satellite symposium to the J Douglas Miller memorial 
meeting held in October 1996 in Edinburgh. In the East Anglia Region the current guidelines have been issued as memo-cards for $A \& E$ officers.

The aim of admission is to observe for deterioration, predominantly caused by intracranial haematomas. The indicators for the development of such lesions are an impaired level of consciousness and presence of a skull fracture. Such patients should therefore undergo regular and frequent neurological observations, and be admitted for at least 12 hours. Following discharge, routine follow up should be considered to identify and treat patients with postconcussion symptoms and signs.

The possible way forward for the management of these patients is adopting a greater emphasis on preventative aspects, and establishing, implementing, and auditing evidence based guidelines. Improved teaching in the form of formal induction seminars and computerised teaching aids is required, and a better understanding of the aetiology and treatment of the postconcussion syndrome.

1 Committee on Trauma of the American College of Surgeons. ATLS manual, 1993.

2 Kirkpatrick PJ. On guidelines for the management of severe head injury. J Neurol Neurosurg Psychiatry 1997;62:10911 .

3 Dacey RG, Alves WM, Rimel RW, Winn R, Jane JA. Neurosurgical complications after apparently minor head injury. $J$ Neurosurg 1986;65:203-10.

4 Nee PA, Phillips BM, Bannister CM. Extradural haematoma in a child after an apparently mild injury. BMJ 1993; 306:1665-6.

Jennett B, MacMillan R. Epidemiology of head injury. BMJ $1981 ; 282: 101-4$

6 Teasdale G, Jennett B. Assessment of coma and impaired consciousness. A practical scale. Lancet 1974;ii:81-4.

7 Rimel RW, Giordani B, Barth JT, Boll TJ, Jane JA. Disability caused by minor head injury. Neurosurgery 1981;9:221-8.

8 Swann IJ, MacMillan R, Strang I. Head injuries at an inner Swann IJ, MacMillan R, Strang I. Head injuries at an inner
city accident and emergency department. Injury $1981 ; 12$ : 274-8.

9 Mendelow AD, Teasdale G, Jennett B, Bryden J, Hessett C, Murray G. Risks of intracranial haematoma in head injured adults. BMJ 1983;287:1173-6.

10 Teasdale GM, Murray G, Anderson E, et al. Risks of acute traumatic intracranial haematoma in children and adults: implications for managing head injuries. BMJ 1990;300: 363-7.

11 Gomez PA, Lobato RD, Ortega SM. Mild head injury: differences in prognosis among patients with a Glasgow Coma Score of 13-15 and analysis of factors with an abnormal CT scan. Br J Neurosurg 1996;10:453-60.

12 Teasdale GM. Head injury. J Neurol Neurosurg Psychiatry 1995;58:526-39.

13 Miller JD, Tocher JL, Jones PA. Extradural haematomaearlier detection, better results. Brain Injury 1988:2:83

14 Miller JD, Murray LS, Teasdale GM. Development of a traumatic intracranial haematoma after a "minor" head injury. Neurosurgery 1990;27:669-73.

15 Reilly PL, Graham DI, Hume Adams J, Jennett B. Patients Reily PL, Graham DI, Hume Adams J, Jennett B. Patients

16 Lee SH, Lui TN. Early seizures after mild closed head injury. J Neurosurg 1992;76:435-9.

17 Briggs M, Clarke P, Crockard A, et al. Guidelines for the initial management after head injury. Suggestions from a group of neurosurgeons. BMJ 1984;288:983-5.
18 Pickard JD, Jackson S, Addison J, Smielewski P, Richards $\mathrm{HK}$. Implementation of head injury guidelines: where are we after two cycles of a regional audit?[abstr] J Neurol Neurosurg Psychiatry 1995;59:206P.

19 Royal College of Radiologists. Costs and benefits of skull radiography for head injury. Lancet 1981;ii:791-5.

20 Royal College of Radiologists Working Party. Patient selection for skull radiography in uncomplicated head injury; a national study by the Royal College of Radiologists. Lancet 1983;i:115-18.

21 Gorman DF. The utility of post traumatic skull X-rays. Arch Emerg Med 1987;4:141-50.

22 The management of acute head injury. Harrogate seminar report No 8. London: DHSS, 1983.

23 de Lacey G, McCabe M, Constant O, Welch T, Spinks C, $\mathrm{McNally} \mathrm{E}$. Testing a policy for skull radiography (and admission) following mild head injury. $\mathrm{Br} \mathrm{J}$ Radiol 1990;63:14-18.

24 Jennett B. Unnecessary $x$ rays. BMJ 1971;ii:399.

25 Heiskanen O, Martilla I, Valtonen S. Prognosis of depressed skull fracture. Acta Chir Scand 1973;139:605-8.

26 Thillainayagam K, McMillan R, Mendelow AD, Brookes MT, Mowat W, Jennett, B. How accurately are fractures of the skull diagnosed in an accident and emergency the skull diagnosed in an accident

27 Gautam V, Leonard EM. Bony injuries in association with minor head injury: lessons for improving the diagnosis of facial fractures. Injury 1994;25:47-9.

28 Duus BR, Boesen T, Kruse KV, Nielsen KB. Prognostic signs in the evaluation of patients with minor head injury. Br J Surg 1993;80:988-91.

29 Stein SC, Spettell C, Young G, Ross SE. Limitations of neurological assessment in mild brain injury. Brain Injury 1993; 7:425-30.

30 Stein SC, Ross SE. Mild head injury: a plea for routine early CT scanning. J Trauma 1992;33:11-13.

31 Stein SC, Ross SE. The value of computed tomographic scans in patients with low-risk head injuries. Neurosurgery 1990;26:638-40.

32 Mohanty SK, Thompson W, Rakower S. Are CT scans for head injury patients always necessary? J Trauma 1991;31: $801-5$.

33 Ros SP, Ros MA. Should patients with normal cranial CT scans following minor head injury be hospitalised for observation? Pediatr Emerg Care 1989; 5:216-18.

34 Shackford SR, Wald SL, Ross SE, et al. The clinical utility of computed tomographic scanning and neurologic examination in the management of patients with minor head injuries. J Trauma 1992;33:385-94.

35 Cooper PR. Traumatic intracranial haematomas. In: Wilkins RH, Rengachary SS, eds. Neurosurgery. New York: McGraw-Hill, 1985:1657-66.

36 Brown SR, Raine C, Robertson CE, Swann IJ. Management of minor head injuries in the accident and emergency department: the effect of an observation ward. J Accid Emerg Med 1994;11:144-8.

37 MacLaren RE, Ghoorahoo HI, Kirby NG. Use of an accident and emergency department observation ward in accident and emergency department observation ward in

38 Working party of the British Society for Antimicrobial Chemotherapy. Infection in neurosurgery. Antimicrobia prophylaxis in neurosurgery and after head injury. Lance 1994;344:1547-5

39 Ward AB, Boughey AM, Aung TS, Barrett K. Use of head injury cards in accident centres. Arch Emerg Med 1992;9 314-16.

40 Rutherford WH, Merrett JD, McDonald JR. Sequelae of concussion caused by minor head injuries. Lancet $1977 ;$ i: $1-4$.

41 Evans RW. The postconcussion syndrome and the sequelae of mild head injury. Neurol Clin 1992;10:815-47.

42 Macfarlane $R$. Headache. The post-concussional syndrome. In: Macfarlane R, Hardy DG, eds. Outcome after head, neck and spinal trauma. Oxford: Butterworth-Heinemann, 1997: and spinal $107-19$.

43 Binder LM. Persisting symptoms after mild head injury: a review of the post-concussive syndrome. J Clin Exp Neuropsychol 1986;8:323-46.

$44 \mathrm{Head}$ injury information pack for relatives. Headway National Head Injuries Association, 7 King Edward Court Nottingham NG1 1EW. 